\title{
¿En dónde está el electrodo?
}

\section{Where is the lead?}

\section{William Fernando Bautista-Vargas ${ }^{a, *}$, Luis Carlos Sáenz-Morales ${ }^{b}$ y Diego Andrés Rodríguez-Guerrero ${ }^{c}$}

\author{
a Departamento de Electrofisiología, Universidad de La Sabana, Bogotá, Colombia \\ b Departamento de Electrofisiología, Fundación Cardioinfantil Instituto de Cardiología, Bogotá, Colombia \\ c Programa de Electrofisiología, Universidad de La Sabana, Bogotá, Colombia
}

\section{PALABRAS CLAVE \\ Marcapasos; \\ Radiografia; \\ Cirugía cardiaca}

\section{KEYWORDS \\ Pacemaker; \\ X-ray; \\ Cardiac surgery}

Paciente de 88 años de edad, mujer, hipertensa, quien consulta por síncope a repetición, con evidencia de bloqueo aurículo-ventricular completo, por lo que requirió un implante de marcapasos transvenoso yugular derecho en la unidad de cuidado intensivo; procedimiento realizado bajo monitoría hemodinámica, con punción única en la vena yugular interna derecha, con posterior captura evidenciada en trazo del electrocardiograma.

En el electrocardiograma se observa ritmo de estimulación QRS con bloqueo de rama derecha, con concordancia

\footnotetext{
* Autor para correspondencia. Bogotá Colombia 2015.

Correos electrónicos: Williambautista679@gmail.com, williambautista679@hotmail.com (W.F. Bautista-Vargas).
}

positiva en las derivaciones precordiales (V1-V6) (fig. 1A), lo cual sugiere una estimulación basal en el ventrículo izquierdo, la imagen radiológica en la placa de tórax fue sugestiva de perforación ventricular derecha con el electrodo, esto asociado a captura frénica (fig. 1B). Posteriormente, se realizó la escanografia de tórax en donde se visualiza un electrodo de estimulación ventricular de localización extracardiaca (fig. 1C), confirmando el diagnóstico de perforación ventricular, que requirió la extracción quirúrgica del electrodo.

La incidencia de esta complicación es hasta del $0.57 \%$ reportada en la literatura, los factores de riesgo reportados son: la dificultad para el paso del electrodo al ventrículo derecho y la cifoescoliosis ${ }^{1,2}$.

Las complicaciones relacionadas con el implante de los dispositivos se presentan hasta en el $7 \%$ de los $\operatorname{casos}^{3}$. La perforación es una complicación que se puede presentar hasta en el $1 \%$ de los implantes, estas se han dividido en agudas (dentro de las primeras 24 horas) y tardías (posterior a 30 días del implante $)^{4}$; reportándose más casos en relación a los electrodos de fijación activa y en menor frecuencia a los electrodos de fijación pasiva, estas últimas teniendo un curso clínico más tolerable por el paciente, con los diagnósticos más tardíos ${ }^{5}$.

Como factores de riesgo asociados a la perforación durante el implante del marcapasos definitivo se han identificado: el uso de los electrodos de fijación activa, el índice de masa corporal $<20$, las mujeres, los pacientes añosos, el uso previo de los electrodos de estimulación transitoria. En relación a las perforaciones tardías el uso de los 


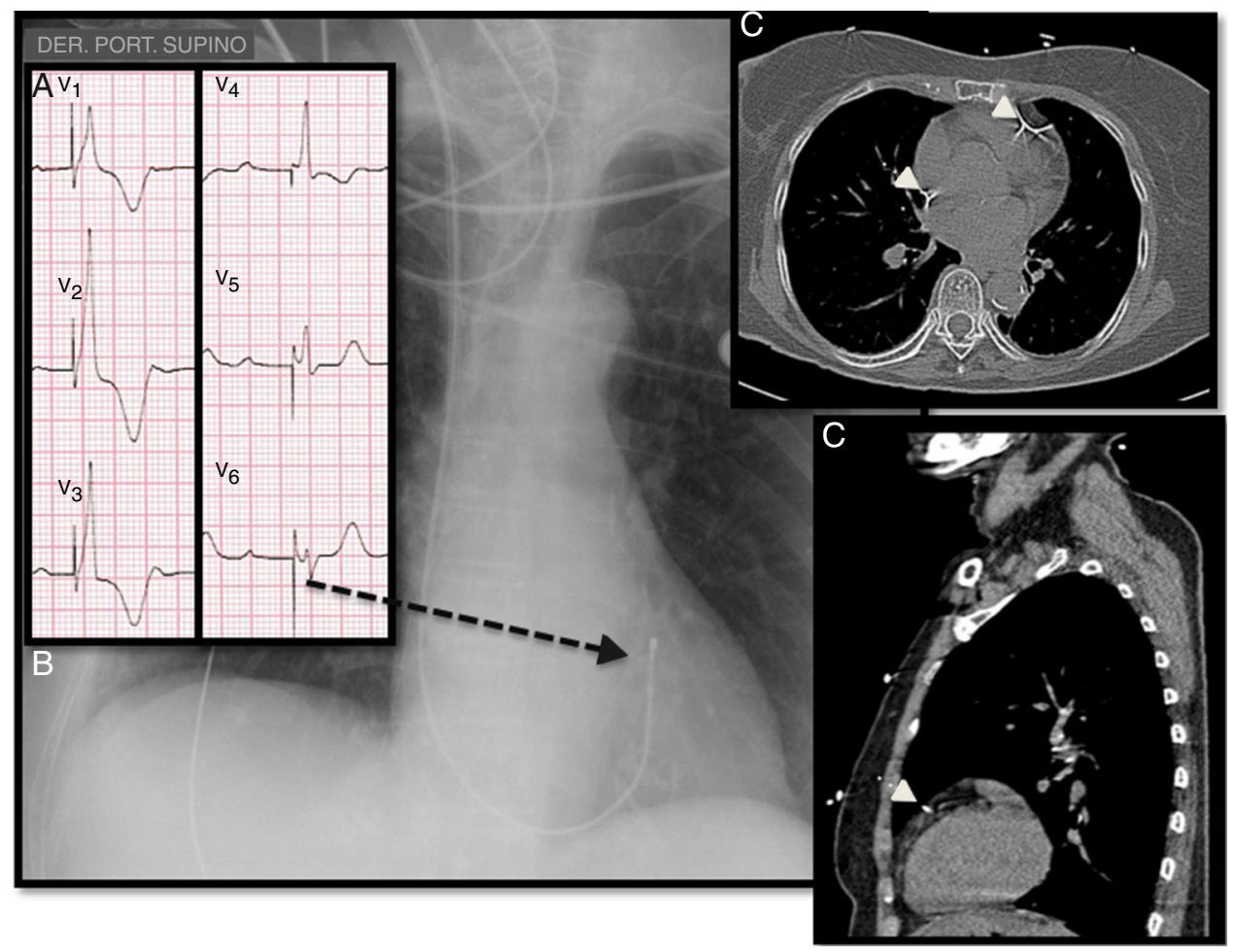

Figura 1 A. Electrocardiograma, ritmo de estimulación con electrodo endocárdico, con morfología de bloqueo de rama derecha, transición tardía.

B. Radiografía de tórax, donde se muestra la posición inusual del electrodo de estimulación transvenoso. C. TAC de tórax corte axial y sagital donde se observa el extremo proximal y el distal del electrodo.

electrodos de fijación pasiva, con diámetros pequeños, posiciones inestables, en posición ventricular ${ }^{4,6}$.

El hallazgo clínico reportado en relación a la perforación ventricular es variado, presentando: alteraciones del censado, la estimulación, la captura de músculos en la vecindad cardiaca, la perforación ósea (costillas), la sepsis y el shock séptico ${ }^{7,8}$.

En conclusión, la perforación ventricular con los electrodos de estimulación transitoria en manos expertas es relativamente infrecuente menor al $1 \%$. Esta es más común en pacientes con: la cifoescoliosis y los accesos del electrodo al ventrículo derecho laboriosos. Debe sospecharse cuando se presentan alteraciones de censado, captura en el electrocardiograma, curso clínico tórpido, radiografía con imágenes inusuales de posición del electrodo. La presencia de perforación con el electrodo ventricular transitorio se convierte en una complicación potencialmente fatal y en un factor de riesgo para las perforaciones relacionadas con el implante de los electrodos de estimulación definitivos.

\section{Bibliografía}

1. Santana-Cabrera L, Pérez-Acosta G, Manzanedo-Velasco R, Sánchez-Palacios M. Perforation of right ventricle with cardiac tamponade following pacemaker implantation. International Journal of Critical Illness and Injury Science. 2011;1(2): 169-70.

2. Trigano JA, Paganelli F, Ricard P, Ferracci A, Avierinos JF, Lévy $S$. Heart perforation following transvenous implantation of a cardiac pacemaker. Presse Med. 1999 Apr 24;28(16):836-40.

3. Hirschl DA, Jain VR, Spindola-Franco H, Gross JN, Haramati LB. Prevalence and characterization of asymptomatic pacemaker and ICD lead perforation on CT. PACE - Pacing Clin Electrophysiol. 2007;30(1):28-32.

4. Ramírez MF, Ching CK, Ho KL, Teo WS. The attack of the $52 \mathrm{~cm}$ lead: An unusual case of late cardiac perforation by a passivefixation permanent pacemaker lead. Int J Cardiol [Internet]. 2007;115(1):E5-7.

5. Tziakas D, Alexoudis A, Konstantinou F, Chalikias G, Stakos D, Bougioukas $\mathrm{G}$. A rare case of late right ventricular perforation by a passive-fixation permanent pacemaker lead. Europace [Internet]. 2009;7(11):968-9.

6. Chemello D, Subramanian A, Glover BM, Ing D. Right ventricular perforation by a passive-fixation pacemaker lead. Arq Bras Cardiol. 2011;96(5):e95-7.

7. Katoh M, Sugimura Y. Pacemaker lead perforation through the right ventricle. Intern Med. 2014;53:2831.

8. Singhal S, Cooper JM, Cheung AT, Acker MA. Rib Perforation From a Right Ventricular Pacemaker Lead. Circulation [Internet]. 2007;115(14):e391-2. 